\begin{tabular}{ccc}
\hline International Journal of Engineering \& Technology \\
SPC & Website: www.sciencepubco.com/index.php/IJET \\
Research Paper & $87-91$ \\
\hline
\end{tabular}

\title{
Price escalation of area surrounding properties along metro line using GIS, A comparative study of Mumbai metro and proposed Pune metro
}

\author{
Dr. Ushadevi Patil ${ }^{1 *}$, Omkar U. Mithe ${ }^{2}$ \\ ${ }^{1}$ Professor in Civil Department, D.Y Patil Institute of Technology, Pimpri, Pune. \\ ${ }^{2}$ PG Student, Department of Civil Engineering, D.Y PIET, Ambi, Pune \\ *Email: patilushadevi.civil@gmail.com
}

\begin{abstract}
Introduction of a transit megaproject like Metro railway in any city is seen as the effective booster for real estate sector for that city. Many cities worldwide and in India also has witnessed a considerable increase in rates of properties located along metro lines, also the areas situated around metro stations within a $500 \mathrm{~m}$ buffer zone has both positive and negative impacts on their property values. It is not necessary that the properties will show only positive effect, sometimes it may happen that due to noise and increased presence of commuters caused by the metro railway the area in the immediate vicinity of metro railway may show negative impact i.e. rates may decrease in that area. Present project firstly focuses on finding out the effect of Mumbai metro line on surrounding area using GIS and then comparing those results for obtaining corresponding values for proposed Pune metro. Initially focus will be on Mumbai metro and outcome of the same will be evaluated for proposed Pune metro. The data required for project has been collected from various government agencies like MMRDA, PCNTDA and DRS. The paper concludes with the brief explanation of alternate method of carrying out the same study.
\end{abstract}

Keywords: Transit Oriented development (TOD), Impact of proximity, Geographical Information System(GIS), Metro Rail, DP's.

\section{Introduction}

Pune has witnessed huge industrial growth since 2000. It is the only city which is not the capital of any state and yet manages a place in top 10 cities of India. Due to its geographical location, weather, IT park, Educational institutes, Automobile and various industries, culture and history it has always attracted people from various parts of India as well as Maharashtra. But, with all these advantages there comes a negative side also.

Meeting the day to day needs of these many large numbers of people, the city lacks on many grounds. One of the most pressing problems in pune city today is that of traffic. Traffic conditions in pune city have reached up to brim and are getting worsened day by day. To solve this problem the government has decided to introduce a Metro railway project in pune city to be completed in two phases. Phase 1 consists of two lines, from Pimpri to Swargate and from Vanaj to Ramwadi. Phase 2 again consists of two lines from Deccan gymkhana to Bund garden and ASI to Hinjewadi. For present project the study area finalized is from Chinchwad to Dapodi. The Metro project in any city has a certain impact on real estate sector of that city. In the same way rates of properties in the vicinity of metro line will get affected both in positive as well as negative way. For predicting the future rates a comparison of Pune metro is done with Mumbai metro as Line 1 (Versova-Andheri-Ghatkopar) is fully functioning since 2013. The data required for project has been collected from various govern- ment agencies like Mumbai Metropolitan Regional Development Authority, Pimpri Chinchwad New Town Development Authority and Department of Registration and Stamps (government of Maharashtra website). The Geographical information system (GIS) and Global mapper software has been used for geo referencing, digitization, preparing maps and attribute table purpose. The obtained results and conclusions show that metro railway has a mixed impact on property values. Some areas have shown increase in rates and other has shown decrease. The paper concludes with the brief explanation of alternate method of carrying out the same study [6] to [13].

\section{Literature review}

In the past many studies has been carried out by various researchers worldwide to identify the possible impact of metro railway line on surrounding area properties. Some of them are as follows:-

A. There are both positive and negative impacts of rail transit system on nearby areas. In the paper the author Roderick B. Diaz et al. gives a summary of various studies carried out to examine the impact rail transit on property values. The authors give general conclusions as to how the impact is. Further, in assessment of positive impacts they found out that one bedroom apartment units within a quarter-mile of the Pleasant Hill BART (Bay Area Rapid Transit System) station in suburban Contra Costa County, east of San Francisco, 
rented for approximately $10 \%$ more per square foot than one bedroom units away from BART. The opposite occurred on the north side. For every 100 feet a property was closer to the East Line, property values dropped by $\$ 965$. This negative effect may be due to such factors as noise, perceptions of crime, and visual intrusion. Lastly authors concluded that overall there is positive effect and that transit systems benefit any city in two ways. Firstly it increases the accessibility to other parts of the town and secondly, it enhances the property value [1].

B. Urban rail transit system plays an important role in one's life. Not only has it increased the value of property but also citizen's social activities. In this paper the author Xu Zhang et al. has used the panel data on housing prices and urban rail transit facilities for 35 Chinese cities for 2002 to 2013, for the determination of effect of rail transit facilities on housing prices quantitatively. To understand the relationship between rail transit facilities and housing prices the authors used correlation analysis. Authors found out that quantitatively, a $1 \%$ increase in rail transit mileage improves housing prices by $0.0233 \%$. The results highlight the importance of other factors (e.g., per capita GDP, land price, investment in real estate and population density) in determining housing prices. Lastly authors conclude that this study is of practical significance, as it provides relative information for policy makers to use when applying regulatory powers to improve urban functions while stabilizing real estate prices. The central government should take utmost precautions to mitigate economic fluctuations [2].

C. The selection of area while buying any property is very important. As the buyer will always see to it that property he or she buys is beneficial to him or her in every possible way. In the paper the author Eric Pels et al. gives answer to the question that what is the impact of railway station proximity on property value. There are various methods of studying the impact of metro railway on property values, but most common of them all is hedonic regression which includes mathematical modelling. It provides statistical synthesis of empirical research focused on a common research question. It includes the differences in study settings that are expected to explain the variation in the findings of the studies. A total of 73 observations has been made using tool so that more precise results can be obtained. Authors found out that in general there is higher positive impact on commercial property values. Finally authors conclude that commuter railway stations have had a significantly higher impact on property values compared to light or heavy railway/Metro stations. Their higher service coverage adds to the attraction of the area surrounding the stations. This will affect the value of properties around commuter railway stations [3].

D. When any rail transit system is introduced in a city, it is a general perception of people that it will have certain positive effect on property value. In this paper the author Amir Forouhar compares price trends before and after the opening of stations. The effect is estimated for treated and control properties of the metro stations using both trend analysis and a difference-indifferences model. The paper uses a Difference-in-Differences (DID) method as a statistical technique to calculate the effect of a treatment (adding or expanding a transit line) on an outcome (property value) by comparing the average change over time for a treatment group, compared to a control group. DID models attempt to remove biases in comparisons between the treatment and control group that could be the result from permanent differences between those groups, as well as biases from comparisons over time in the treatment group that could be the result of trends. The authors found that an overall negative effect of the metro stations on the sales value of residential properties located in Tehran's affluent neighborhoods. On the contrary, the effect is positive and high for properties located close to the southern stations in the poor and run-down neighborhoods of the city [4].
E. The construction of subways and metro for any major city like Tianjin is very beneficial to its economy. The major change which can be seen is the acceleration of the property values in housing near subway stations. In this paper the author Hui Sun et al. has selected Tianjin, the largest open coastal city in Northern China as study area for their project. The authors analyze the sphere of influence of Tianjin Metro Line 3 on real estate prices. The results show that the housing located at the closest distance to the station has experienced a significant impact. The regression results for the entire region show that the coefficient of the distance to the nearest subway station is The coefficient reaches -0.247471 ; of which the absolute value is higher than the absolute value of the coefficient of the distance to the nearest subway station in the regression of the entire subway line 3 which is -0.099011 .In the center area, the influence coefficient of the distance to the nearest subway line 3 stations is -0.079166 . This means that if the housing is $1 \mathrm{~km}$ from each track site, the prices will increase $7.9 \%$. Finally the authors conclude that the construction of a subway plays a significant role in promoting increases in the surrounding land prices [5]

F. -0.099011. Namely, if the property is located $1 \mathrm{~km}$ from the station, its property prices increase by $9.9011 \%$. For nonurban centers, subway line 3 stations have a very strong impact on housing prices.

\section{Methodology and data collection}

Procedure and methodology includes following steps:-

1. First and foremost step to begin the project work is to identify the area in which the work is to be carried out. For this, identification of research problem and research objectives is necessary.

2. After finalization of study area, extensive literature survey is done. In this, the work done by various authors in past is studied in detail and the procedure carried out by them is analysed. Further their results, conclusions and findings are also carefully observed.

3. Now, based on the above literature survey all the necessary data including photographs of plots of private ownerships and government ownership, Development plans with CTS numbers of finalized study area from MMRDA (Mumbai Metropolitan Regional Development Authority), ready reckoner rates of various years for both Pune (Pimpri Chinchwad New Town Development Authority) and Mumbai and actual rates of properties (around 410 properties) from website of 'Department of registration and stamps' Government of Maharashtra website were collected.

4. After collection of all the above necessary data, it is merged with GIS and global mapper software for analyzation. The development plans with CTS numbers are georeferenced (assigning real world coordinates to each pixel of the raster) with GIS so that vector data file is created. 


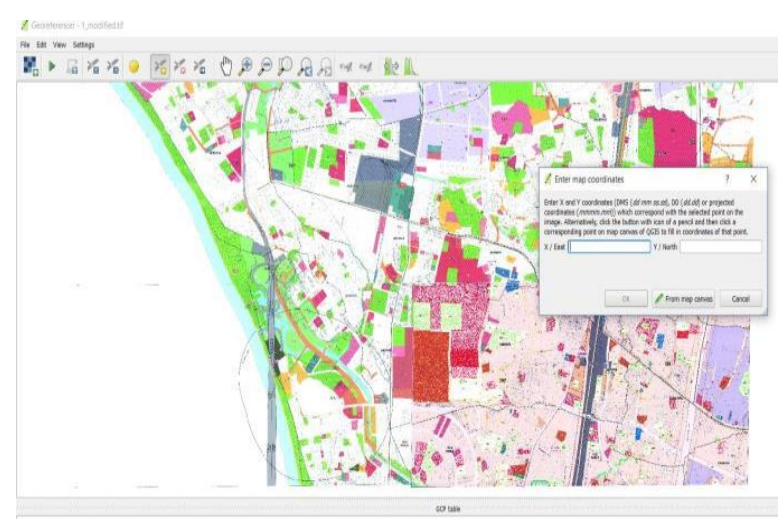

Fig. 1 Created Vector data file

5. After georeferencing and creation of vector file the metro line and plots surrounding it (Mumbai Metro) were digitized. Digitization can be defined as the conversion of texts and pictures into a digital form that can be processed by a computer. For achieving more accurate and precise results around 2200 plots of varying size and type were digitized using area feature command in global mapper software.

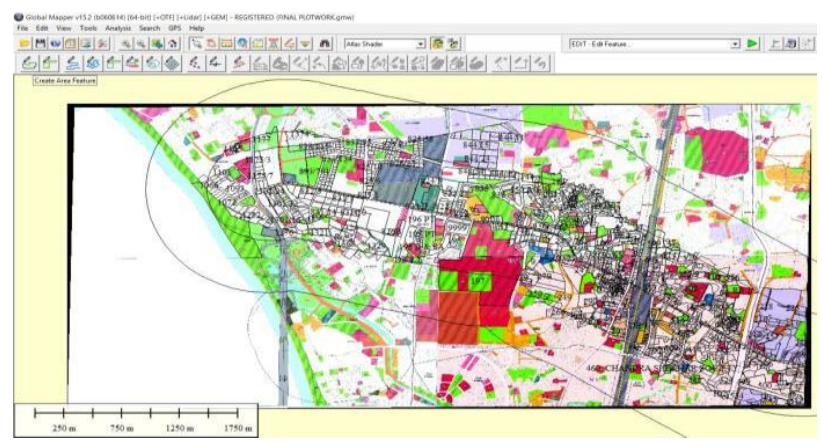

Fig.2 Digitized map

6. While digitizing survey number of plots, 2013 ready reckoner rate and 2017 ready reckoner are added as attributes.

7. After digitization is complete, using the 'create layer wise statistics report' command the attribute table is imported as an excel sheet (.xlsx extension).

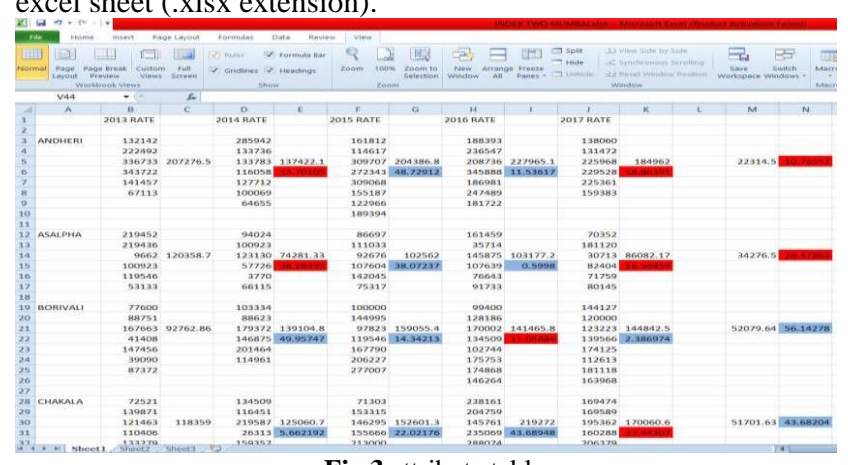

Fig 3 attribute table

8. Then next step is to calculate \%increase or \%decrease in ready reckoner rates as well as actual land rates for Mumbai areas along a span of 4 years from 2013 to 2017 i.e. from the commencement of metro to 4 years

9. Results obtained from above analysis are then tabulated and graphs were prepared

10. The results obtained for Mumbai metro are then compared with proposed pune metro, the areas along the metro line in which there is \%increase or \%decrease in ready reckoner rates as well as actual land rates are identified and year 2021 rates are predicted, graphs for the same are prepared and Suitable conclusions were drawn.

\section{Results}

After collecting all the necessary data and doing all the procedure five graphs were prepared.

4.1 First graph shows the variation in average actual property rates (Index II rates) of 10 areas of Mumbai namely Andheri, Asalpha, Borivali, Chakala, Ghatkopar, Goregaon, Juhu, Kurla, Marol and Versova over the years 2013, 2014, 2015, 2016 and 2017. It represents the general trend of five years i.e. from the commencement of metro to 4 years.

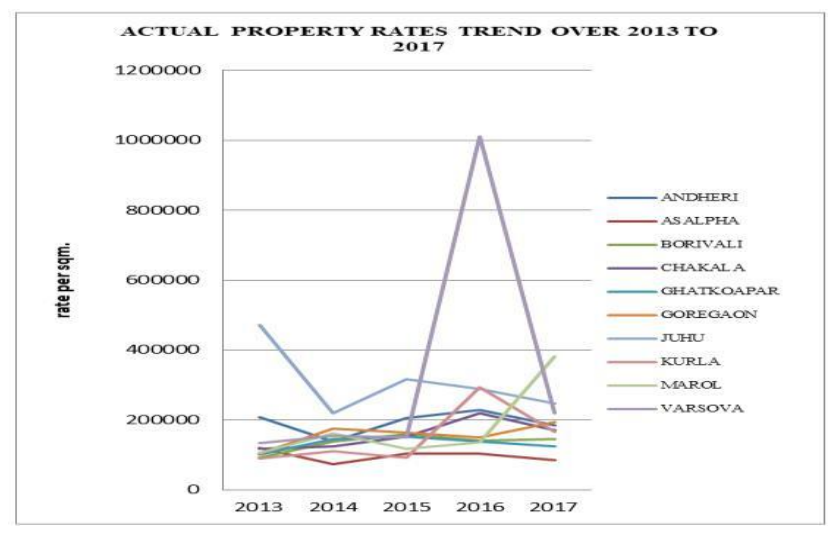

Fig.4 Average actual property rates

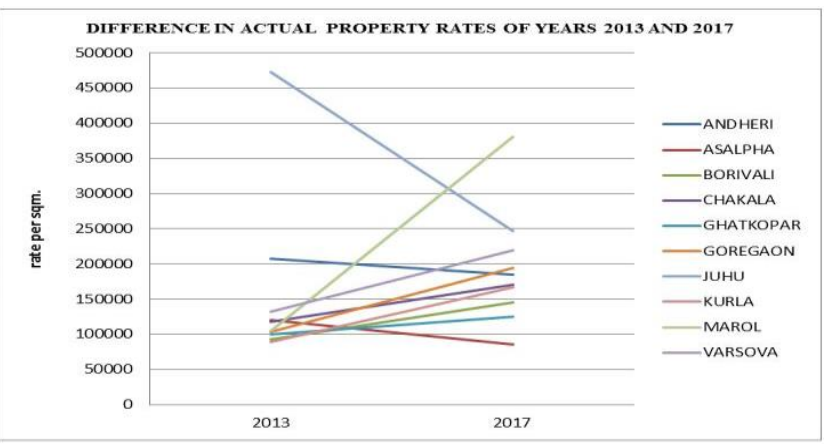

Fig.5 Difference in average actual property rates

4.2 Second graph shows the difference in average actual property rates (Index II rates) of 10 areas of Mumbai namely Andheri, Asalpha, Borivali, Chakala, Ghatkopar, Goregaon, Juhu, Kurla, Marol and Versova over the years 2017 and 2013. It can be seen that in some areas property rates have decreased and in some areas property rates have increased. No, particular pattern can be seen in areas regarding the increase or decrease in rates. Although Andheri is a metro station, it is evident from the graph that its rate has been decreased.

4.3 Third graph shows the projected average actual property rates (Index II rates) of year 2021 of 5 areas of PCMC namely Bhosari, Chinchwad, Dapodi, Pimple Gurav and Pimple Saudagar which are compared with Chakala, Andheri, Marol, Ghatkopar and Kurla of Mumbai respectively on the basis of various parameters such as geographical position with respect to metro line, industrial hub, amenities, institutions, population density, district headquarters, slum area, government offices etc. 


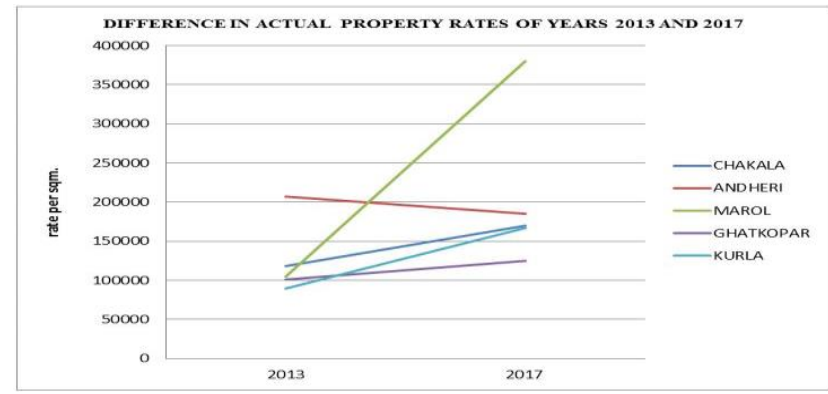

Fig. 6 Difference in actual property rates

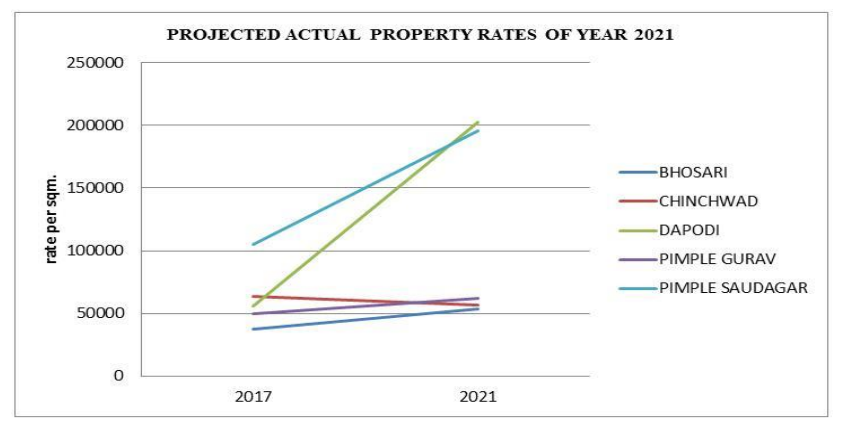

Fig. 7 projected average actual property rates

4.4 Fourth graph shows average increase in ready reckoner rates (Mumbai) from year 2013 to 2017 of 4 categories namely residential / industrial, office, land and shops. Further these rates were compared to Pimpri Chinchwad ready reckoner rates to get the projected rates of year 2021

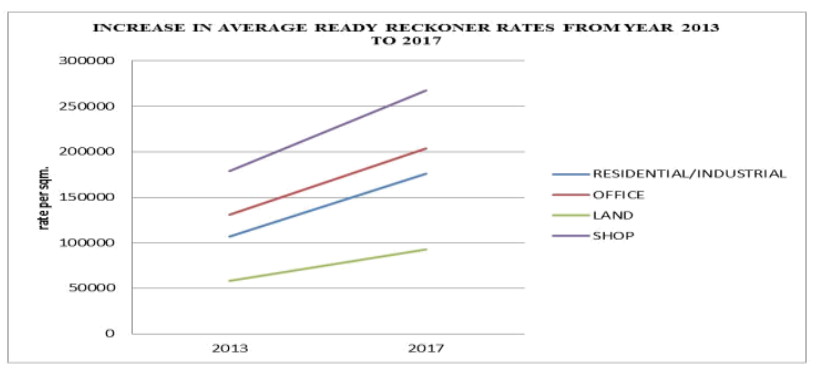

Fig.8 Increase in average ready reckoner rates

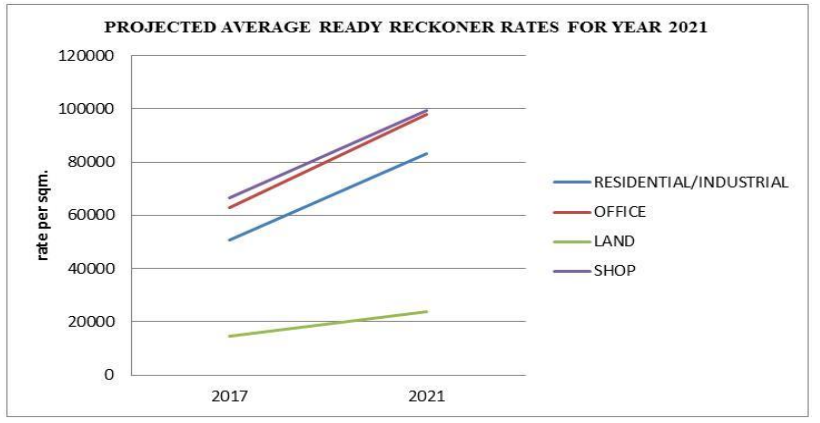

Fig. 9 Projected average ready reckoner rates

\section{Conclusion}

As it is evident from the literature review and results founded above that metro project for any city has both positive and negative effects i.e. some areas around metro line shows increase in land value rates and some areas shows decrease in land value rates. In Mumbai city also a mixed effect of metro project can be seen. Andheri, Asalpha and Juhu have seen decrease in rates by $10.76 \%, 28.47 \%$ and $47.75 \%$ respectively over the years 2013 to 2017. This is due to the fact that with the ease of transportation people tend to move to outer peripheral areas of Mumbai city and buy properties there. Also due to increase in traffic, pollution, noise and daily commuters travelling by metro, people intend not to buy property near to metro station but away from it. In contrast to this Borivali, Chakala, Ghatkopar, Goregaon, Kurla, Marol and Versova have seen increase in rates (as an obvious effect) by $56.14 \%, 43.68 \%, 24.50 \%$, $87.34 \%, 86.22 \%, 261.78 \%$ and $65.39 \%$ respectively over the years 2013 to 2017 . This is due to the reason that transit projects usually have positive effect on property values due to increased accessibility and beautification of area, negative effect being the rare case. With the help of Mumbai metro case study, predictions for the Pune metro has been made (for the year 2021) which will start functioning by July 2019(estd).

Five areas of PCMC (Pimpri Chinchwad Municipal Corporation) has been selected which are located around proposed Pune metro line (phase 1) namely Bhosari, Chinchwad, Dapodi, Pimple Gurav and Pimple Saudagar. Based on different parameters these areas were compared with Mumbai areas. Such as Bhosari is compared to Chakala and is expected to have an increase of $43.68 \%( \pm 10 \%)$. Likewise Chinchwad is compared to Andheri and is expected to have a decrease of $10.76 \%( \pm 10 \%)$. In the same way Dapodi is compared with Marol, expected increase of $261.78 \%$ ( $\pm 10 \%$ ). Pimple Gurav compared to Ghatkopar, expected increase of $24.50 \%( \pm 10 \%)$. At last Pimple Saudagar is compared to Kurla, expected increase of $86.23 \%$ ( \pm $10 \%)$. Second part of project was to estimate year 2021 ready reckoner rates in Pimpri Chinchwad based on increase in ready reckoner rates over the years 2013 to

2017 in Mumbai. Study shows that average increase in 'residential / industrial' rate is $64.69 \%$. Likewise average increase in 'offices' rate is $55.59 \%$. Average increase is 'land' rate is $59.87 \%$ and average increase in 'shop' rate is

49.65\%. It can be said that proposed Pune metro will have a mixed effect on real estate sector of Pimpri Chinchwad i.e. some areas will show increase in rates and some areas will show decrease in rates.

\section{References}

[1] Roderick B. Diaz, Booz Allen and Hamilton, Impacts of Rail Transit on Property Values.

[2] Xu Zhang, Xiaoxing Liu, Jianqin Hang, Dengbao Yao and Guangping Shi, (2016) Do Urban Rail Transit Facilities Affect Housing Prices? Evidence from China. www.mdpi.com / journal / sustainability

[3] Ghebreegziabiher Debrezion, Eric Pels and Piet Rietveld, (2004) The Impact of Railway Stations on Residential and Commercial Property value. Tinbergen institute

[4] Amir Forouhar, (2016) Estimating the impact of metro rail stations on residential property values: evidence from Tehran. Public Transp DOI 10.1007/s12469-016-0144-9.

[5] Hui Sun, Yuning Wang, and Qingbo Li, (2016) the Impact of Subway Lines on Residential Property Values in Tianjin: An Empirical Study Based on Hedonic Pricing Model. Hindawi Publishing Corporation Discrete Dynamics in Nature and Society Volume 2016, Article ID 1478413.

[6] Xin Janet Ge, Heather Macdonald and Sumita Ghosh, (2012) Assessing the impact of rail investment on housing prices in northwest Sydney. 18th Annual Pacific-Rim Real Estate Society Conference Adelaide, Australia.

[7] Sisi Yan, Eric Delmelle and Michael Duncan, (2012) the impact of a new light rail system on single-family property values in Charlotte, North Carolina. The journal of land use and transport. Volume 5, No. 2.

[8] Rajeeshwaran Moorthy and Neo Jeronn. (2014) Public Transportation Effect on the Rising of Property Prices in Malaysia: A 
Correlation Study of MRT Project. Copyright @ 2014 Society of Interdisciplinary Business Research (www.sibresearch.org). ISSN: 2304-1013 (Online); 2304-1269 (CDROM).

[9] . Prof. H. M. Shivanand Swamy and Sagar Setia. Metro Rail Transit System Impacts On Land-use And Land Values in Bangalore, India.

[10] (2013) Delhi Metro and its influence on real estate prices.Makaan.com

[11] Parsons Brinckerhoff, (2001) The Effect Of Rail Transit On Property Values A Summary Of Studies. Research carried out for Project 21439S, Task 7 NEORail II, Cleveland, Ohio

[12] A. Shankar, (2015) Metro Rail -An Unmatched Real Estate Catalyst. National director \& Head, Urban Solutions (Strategic Consulting), JLL India

[13] Thakurdesai PA, Kole PL \& Pareek RP (2004), Evaluation of the quality and contents of diabetes mellitus patient education on Internet. Patient Education and Counseling 53, 309-313 